\title{
COVID-19: Critical Role of Angiotensin 1-7 in ACE2 Modulation
}

\section{Dear Editor,}

With the declaration of Novel Coronavirus Disease 2019 (COVID-19) as pandemic by World Health Organization (WHO), many countries have taken drastic measure to enforce movement control to curb COVID-19 outbreak. On 23 January 2020, it was reported that Malaysia had 4 patients suspected to have contracted the COVID-19. On the same day, Singapore confirmed its first case of COVID-19. ${ }^{1}$ The first confirmed COVID-19 case reported in Malaysia was on 24 January 2020. To date, WHO has reported a total of 5.6 million confirmed cases, with 353,373 confirmed deaths among 216 countries around the world. ${ }^{2}$ Current evidence suggests that COVID-19 patients could develop rapidly worsening respiratory failure and acute respiratory distress syndrome (ARDS). ${ }^{3}$

Similar to SAR-Cov (Severe Acute Respiratory Syndrome Coronavirus), COVID-19 is believed to be using the same entry point of Angiotensin Converting Enzyme 2 (ACE2) into the human host cells.,5 ACE2 is a carboxymonopeptidase that cleaves at the carboxy-terminal (C-terminal) end of a protein or peptide [6], and is expressed on respiratory and intestinal epithelial cells, endothelial cells, renal tubule cells and immune cells. ${ }^{6-10}$ Tipnis et al (2000) also reported that the mammalian homologue of $\mathrm{ACE}$ has implications on cardiovascular and renal function. ${ }^{11}$ Up to $96 \%$ of ACE2 is available as membrane-bound enzyme, and the minority of ACE2 (1-4\%) presents as a soluble form in blood, urine, and other body fluids. ${ }^{12,13}$ Additionally, the latest study by Wan et al (2020) reported that COVID-19 uses the same receptor-binding motif, as SAR-Cov that directly contacts with ACE2. ${ }^{14}$

There is an intrinsically high renin angiotensin system (RAS) activity in the lungs, creating a relatively higher concentration of ACE2 in the organ. Interestingly, Angiotensin Converting Enzyme (ACE) inhibitors, which are commonly prescribed for hypertension treatment, antagonise specifically the effect of ACE, but not ACE2. [15] ACE2 plays an important role in RAS, by converting Angiotensin II to Angiotensin
1-7 (Ang-(1-7)). ${ }^{6,16}$ The formation of Ang-(1-7) is the requisite biologic effects of ACE2 to Angiotensin II. ${ }^{17,18}$ Nonetheless, Angiotensin I is also converted to Ang-(1-7) via endopeptidases. ${ }^{19}$ Ang-(1-7) provides vasoprotective effects by stimulating nitric oxide production and reduces reactive oxygen species' production. ${ }^{20}$ The disequilibrium of RAS has a significant role in COVID-19 as it is involved in the modulation of the inflammatory response in the lungs. It may seem counter intuitive, but upregulation and higher levels of Ang-(1-7) as well as ACE2 were observed in patients receiving ACE inhibitors or even Angiotensin Receptor Blocker (ARB). ${ }^{14,21}$ Of note is the fact that augmentation of ACE2 activity, as backed by animal in vivo study, could offer vasodilation, antioxidant, anti-inflammation and lung protective effect. ${ }^{22}$

Evidence has shown diabetic and hypertensive patients are susceptible to COVID-19 and face higher mortality rates. ${ }^{23}$ The use of ACE inhibitors and ARB over the expression of ACE2 is debatable until the latest study indicated that these two antihypertensive drugs could increase the mortality rate of patients with COVID-19. ${ }^{24}$ The arguable use of ACE inhibitors and ARB is further supported by Cure and Cumhur (2020), with the rising concern over cardiac arrhythmias and myocarditis events, provoked by increased cardiac ACE2 levels caused by both antihypertensive drugs and thus enhancing the penetration of SARS-CoV-2 into the heart tissue. ${ }^{25}$

However, evidence has shown that ACE2 is not inhibited by ACE inhibitor because ACE and ACE2 are different enzymes. ${ }^{26}$ Literature has shown that ACE2 is consistently increased by ARB especially in cardiac tissue and renal vasculature, but at high doses. ${ }^{26,27}$ Of note is a China study reported which lower mortality rate in COVID-19 hypertensive patients treated with ACE inhibitor/ ARB (adjusted HR, 0.30; $95 \%$ CI, $0.12-0.70 ; P=0.01) .{ }^{28}$ To date, there is no solid evidence to support discontinuation of the use of ACE inhibitor and ARB in COVID-19 patients. ${ }^{29}$ With the lack of evidence to support the possible 
protective effect of ACE2 augmentation rendered by ACE Inhibitor/ ARB, the downstream metabolite of ACE2, Ang-(1-7), provides the possible clue to this dynamic responsiveness.

Hypothetically, as a negative feedback effect, ACE2 level should decrease with elevation of Ang-(1-7) in RAS (Fig. 1). Compared to ACE2, Ang-(1-7) is the downstream metabolite that could exert vasodilation and anti-inflammation effect when it binds to Mas receptor. ${ }^{30-32}$ Despite functioning as a receptor for Ang-(1-7), Mas has important physiological actions in biological active peptide by providing a clear molecular basis. ${ }^{34}$ Treatment with Ang-(1-7) has significantly reduced levels of proinflammatory cytokines, oxidative stress and macrophage infiltration in the lungs. ${ }^{32}$ If this hypothesis is proven, the anti-inflammation and lung protective effect could be warranted with the increase concentration of external Ang-(1-7) albeit with the reduced ACE2 as host cell for SARS-CoV-2. Therefore, the spread of COVID-19 could be diminished with the reduction in the amount of ACE2 which act as host cells. "Emerging and re-emerging infections" seems to be the current trend, and the threat of infections is unlikely to be eradicated abruptly. ${ }^{35}$ Further inroads with broader approaches involving biological agents should be considered to mitigate COVID-19. A proof of concept study would provide the much-needed evidence to support this postulation.

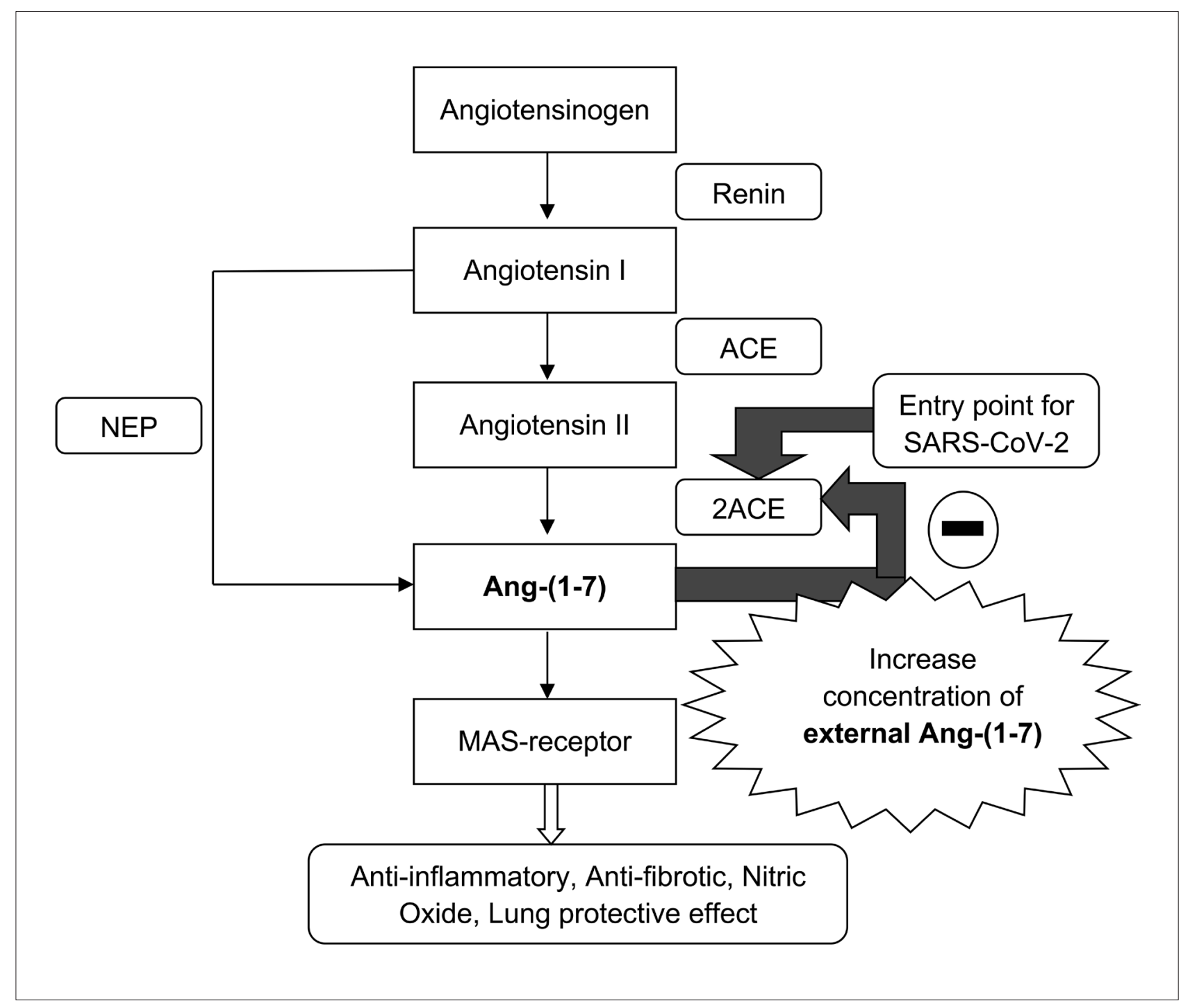

Figure 1. Negative feedback effect of Angiotensin 1-7 [Ang-(1-7)] in Renin Angiotensin System (RAS). 


\section{REFERENCES}

1. Hsu LY, PY Chia, and J.F. Lim, The novel coronavirus (SARS-CoV-2) epidemic. Ann Acad Med Singapore 2020;49(1):1-3.

2. World Health Organization. Coronavirus disease (COVID-19) pandemic 2020. Available from: https:/www.who.int/emergencies/ diseases/novel-coronavirus-2019. Accessed on 29 May 2020.

3. Goh KJ, et al, Rapid Progression to Acute Respiratory Distress Syndrome: Review of Current Understanding of Critical Illness from COVID-19 Infection. Ann Acad Med Singapore 2020;49(3):108-118.

4. Zhou P, et al, A pneumonia outbreak associated with a new coronavirus of probable bat origin. Nature 2020:1-4.

5. $\mathrm{Xu} \mathrm{X}$, et al, Evolution of the novel coronavirus from the ongoing Wuhan outbreak and modeling of its spike protein for risk of human transmission. Science China Life Sciences 2020;63(3):457-460.

6. Donoghue $\mathrm{M}$, et al, A novel angiotensin-converting enzyme-related carboxypeptidase (ACE2) converts angiotensin I to angiotensin 1-9. Circulation research 2000;87(5):e1-e9.

7. Guo Y, et al, Pathogenetic mechanisms of severe acute respiratory syndrome. Virus Res 2008;133(1):4-12.

8. Lukassen S, et al, SARS-CoV-2 receptor ACE2 and TMPRSS2 are primarily expressed in bronchial transient secretory cells. EMBO J 2020;e105114.

9. Jia H, Pulmonary angiotensin-converting enzyme 2 (ACE2) and inflammatory lung disease. Shock 2016;46(3):239-248.

10. Brosnihan KB, et al, Enhanced renal immunocytochemical expression of ANG-(1-7) and ACE2 during pregnancy. Hypertension 2003;42(4):749-753.

11. Tipnis SR, et al, A human homolog of angiotensin-converting enzyme. Cloning and functional expression as a captopril-insensitive carboxypeptidase. J Biol Chem 2000;275(43):33238-43.

12. Serfozo P, et al, Ang II (Angiotensin II) Conversion to Angiotensin-(1-7) in the Circulation Is POP (Prolyloligopeptidase)Dependent andACE2 (Angiotensin-Converting Enzyme 2)-Independent. Hypertension 2020;75(1):173-182.

13. Arendse LB, et al, Novel Therapeutic Approaches Targeting the ReninAngiotensin System and Associated Peptides in Hypertension and Heart Failure. Pharmacol Rev 2019;71(4):539-570.

14. Wan Y, et al, Receptor recognition by novel coronavirus from Wuhan: An analysis based on decade-long structural studies of SARS. Journal of virology 2020.

15. Rice GI, et al, Evaluation of angiotensin-converting enzyme (ACE), its homologue ACE2 and neprilysin in angiotensin peptide metabolism. Biochemical Journal 2004;383(1):45-51.

16. Turner AJ and NM Hooper, The angiotensin-converting enzyme gene family: genomics and pharmacology. Trends in pharmacological sciences 2002;23(4):177-183.

17. Batlle D, et al, Angiotensin-converting enzyme 2: enhancing the degradation of angiotensin II as a potential therapy for diabetic nephropathy. Kidney Int 2012;81(6):520-8.

18. Ferrario CM, et al, Counterregulatory actions of angiotensin-(1-7). Hypertension 1997;30(3 Pt 2):535-41.

19. South AM, DI Diz, and MC Chappell, COVID-19, ACE2, and the cardiovascular consequences. Am J Physiol Heart Circ Physiol 2020;318(5):H1084-H1090.

20. Benter IF, et al, Angiotensin-(1-7) prevents activation of NADPH oxidase and renal vascular dysfunction in diabetic hypertensive rats. Am J Nephrol 2008;28(1):25-33.

21. Zisman LS, et al, Angiotensin-(1-7) formation in the intact human heart: in vivo dependence on angiotensin II as substrate. Circulation 2003;108(14):1679-1681.
22. Tikellis $\mathrm{C}$ and $\mathrm{M}$ Thomas, Angiotensin-converting enzyme 2 (ACE2) is a key modulator of the renin angiotensin system in health and disease. International journal of peptides 2012 .

23. Yan Y, et al, Clinical characteristics and outcomes of patients with severe COVID-19 with diabetes. BMJ Open Diabetes Res Care 2020;8(1).

24. Fang L, G Karakiulakis and M Roth, Are patients with hypertension and diabetes mellitus at increased risk for COVID-19 infection? The Lancet Respiratory Medicine 2020.

25. Cure E and M Cumhur Cure, Angiotensin-converting enzyme inhibitors and angiotensin receptor blockers may be harmful in patients with diabetes during COVID-19 pandemic. Diabetes Metab Syndr 2020;14(4):349-350.

26. Ferrario CM, et al, Effect of angiotensin-converting enzyme inhibition and angiotensin II receptor blockers on cardiac angiotensin-converting enzyme 2. Circulation 2005;111(20):2605-10.

27. Wang $X$, et al, The effects of different angiotensin II type 1 receptor blockers on the regulation of the ACE-AngII-AT1 and ACE2-Ang(17)-Mas axes in pressure overload-induced cardiac remodeling in male mice. J Mol Cell Cardiol 2016;97:180-90

28. Zhang P, et al, Association of inpatient use of angiotensin converting enzyme inhibitors and angiotensin II receptor blockers with mortality among patients with hypertension hospitalized with COVID-19. Circulation research 2020.

29. Tucker ME, ESC Says Continue Hypertension Meds Despite COVID-19 Concern. 2020 [cited 2020 17th May]; Available from: https://www.medscape.com/viewarticle/926838.

30. Dehghani A, S Saberi and M Nematbakhsh, Role of Mas Receptor Antagonist A799 in Renal Blood Flow Response to Ang 1-7 after Bradykinin Administration in Ovariectomized Estradiol-Treated Rats. Adv Pharmacol Sci 2015;2015:801053.

31. Wang J, et al, The ACE2-Ang (1-7)-Mas receptor axis attenuates cardiac remodeling and fibrosis in post-myocardial infarction. Mol Med Rep 2017;16(2):1973-1981.

32. Papinska AM, et al, Long-term administration of angiotensin (1-7) prevents heart and lung dysfunction in a mouse model of type 2 diabetes $(\mathrm{db} / \mathrm{db})$ by reducing oxidative stress, inflammation and pathological remodeling. Pharmacological research 2016; 107:372-380

33. Tesanovic S, et al, Vasoprotective and atheroprotective effects of angiotensin (1-7) in apolipoprotein E-deficient mice. Arteriosclerosis, thrombosis, and vascular biology 2010;30(8):1606-13.

34. Santos RA, et al, Angiotensin-(1-7) is an endogenous ligand for the G protein-coupled receptor Mas. Proc Natl Acad Sci USA 2003;100(14):8258-63.

35. Wong SY and BH Tan, Megatrends in infectious diseases: the next 10 to 15 years. Ann Acad Med Singapore 2019;48(6):188-94.

Ching Siang Tan, ${ }^{1}$ Bpharm (Hons), MSc (Pharmacy Practice), PhD (USM),

Siang Fei Yeoh, ${ }^{2}$ BPharm(Hons), MClinPharm,

Chiau Ming Long, ${ }^{3}$ BPharm(Hons), MClinPharm, PhD

${ }^{1}$ School of Pharmacy, KPJ Healthcare University College, Malaysia

${ }^{2}$ Department of Pharmacy, National University Health System, Singapore

${ }^{3}$ PAP Rashidah Sa'adatul Bolkiah Institute of Health Sciences, Gadong, Universiti Brunei Darussalam, Brunei Darussalam

Address for Correspondence: Associate Professor Dr Tan Ching Siang, School of Pharmacy, KPJ Healthcare University College, Malaysia

Email: chingsiang9@hotmail.com 